\title{
Focal Extraction of Surface-Bound DNA from a Microchip Using Photo-Thermal Denaturation
}

BioTechniques 28:1006-1011 (May 2000)

\author{
Kenji Yasuda, Kazunori \\ Okano $^{1}$ and Shin'ichi \\ Ishiwata $^{2}$ \\ The University of Tokyo, \\ ${ }^{1}$ Hitachi, Ltd. and ${ }^{2}$ Waseda \\ University, Tokyo, Japan
}

\section{INTRODUCTION}

Purification and analysis of DNA from a mixture of cell extract are fundamental in molecular and cellular biology and molecular diagnosis. In purification, a DNA library constructed from cloned DNA is usually used. Although the cloning method is widely used and is suitable for the preparation of a large number of DNA, the cultivation step of this method is laborious and time consuming. Recently, molecular biology has moved rapidly towards the study of functional genomics (10) and proteomics. These studies require rapid selection and collection of the target parts of a gene and mRNA from crude samples $(3,6)$. Although the latest chip technology is capable of simple, highthroughput analysis in distinguishing different sequences of DNA by hybridization detection between a chipbound probe DNA and sample DNA $(1,2,8,9)$, it has not yet been applied to high-throughput purification of DNA, in which a portion of the sample DNA having particular DNA segments is picked up for further analysis.

Here, we propose a new type of DNA purification method using a photo-thermal approach to extract specific DNA bound on a microchip surface. This method is based on the principle that a focused IR beam heats a spotted area on the metal-coated chip surface (4) and that the resulting increase in temperature leads to denaturation of the sample probe DNA. As shown in Figure 1, the method consists of the following four steps: (i) sample DNA are loaded onto a chip surface coated with a metal thin layer, on which a group of surface-bound probe DNA are immobilized; (ii) sample DNA is hybridized with probe DNA; (iii) the chip surface is washed, the hybridized sample DNA are observed and the plate is spot-heated to extract DNA from the spotted area; and (iv) the released sample DNA is collected. The advantages of this spot-heating method are that it provides non-contact, spatially distributed denaturation and faster relaxation time in the increase in temperature. It should thus prove highly suitable for extracting target DNA individually from a chip surface on which a crude DNA mixture has been loaded. Steps $i$ and $i i$ have already been realized in DNA chip technology $(1,2,8,9)$, but steps iii and $i v$ are not yet tested. Here, we focused on steps $i i i$ and $i v$, namely the technique for areaspecific denaturation and release of surface-bound DNA and subsequent collection of the released DNA.

\section{MATERIALS AND METHODS}

\section{Photo-Thermal Denaturation Microscopy System}

Figure 2 shows a diagram of the photo-thermal denaturation microscopy system for area-specific extraction of surface-bound DNA. It consists of three different optical units for phase-contrast, fluorescence and 1053-nm IR laser irradiation, respectively (Nd:YLF laser, 1053-100p; Amoco Laser, Naperville, IL, USA; maximum power 100 $\mathrm{mW}$ at the focal point when $\mathrm{a} \times 10 \mathrm{ob}-$ jective lens is used). Different probe DNA areas in the matrix are distinguished by phase-contrast microscopy. The amount of surface-bound sample DNA on the microchip was measured by fluorescence microscopy. Phasecontrast and fluorescence images were simultaneously acquired with a dualview microscopy system $(4,5,7)$ : the former through a charge-couple device (CCD) camera and the latter through a CCD camera equipped with an image intensifier. The area of DNA denaturation was brought into focus using the 
fluorescence image, and the IR laser beam irradiated the spotted area. The intensity of the IR laser beam can be controlled up to $100 \mathrm{~mW}$ at the focal position on the microchip.

\section{Preparation of DNA Chip}

Probe DNA was immobilized on a 6nm-thick chromium-coated glass plate. The chromium surface was modified with an active residue having a glysidoxy group for coupling dsDNA (619 bp, 0.5 pmol, $0.5 \mu \mathrm{L}$ ) onto the surface by the following two reaction steps. First, the glass plate with a chromium surface $(45 \times 25 \times 0.4 \mathrm{~mm})$ was dipped into a solution of 3-glysidoxypropyltrimethoxysilane for $1 \mathrm{~h}$ at room temperature $\left(25^{\circ} \mathrm{C}\right)$ and dried at $110^{\circ} \mathrm{C}$ for 30 min. Next, dsDNA was prepared with an amino residue at the $5^{\prime}$-terminus of one strand and sulforhodamine-101 fluorophore at the $5^{\prime}$-terminus of the other strand so as to immobilize the DNA through its amino residue with glysidoxy groups on the chip surface. The dsDNA was a product amplified from a cloned human DNA. The clone has M13 priming sites 5'-CATGACTGGCCGTCGTT-3' at both ends. It was amplified by PCR with Taq DNA polymerase (Amersham Pharmacia Biotech, Little Chalfont, UK) and two primers, 5'-fluorophore-AACGACGGCCAGTCATGCG-3' and 5'-NH2-AACGAC-
GGCCAGTCATGTG-3'. Thermal cycling for PCR was carried out $35 \times$ at $94^{\circ} \mathrm{C}$ for $30 \mathrm{~s}, 60^{\circ} \mathrm{C}$ for $30 \mathrm{~s}$, and $72^{\circ} \mathrm{C}$ for $60 \mathrm{~s}$. A solution of the product (10 $\mu \mathrm{M}$ dissolved in $0.2 \mathrm{M}$ sodium carbonate buffer, $\mathrm{pH}$ 9.5) was dropped onto the activated chip, incubated at $50^{\circ} \mathrm{C}$ for 45 min and kept at room temperature so that the $5^{\prime}$-terminus of the probe DNA was attached to the chip. The quantity of immobilized DNA was checked by fluorescence microscopy with a confocal scanning fluorescence microscope (LSM-200; Olympus, Tokyo, Japan).

\section{Recovery of DNA Using Photo- Thermal Denaturation}

The DNA chip was rinsed and overlaid with $5 \mu \mathrm{L} 20 \mathrm{mM}$ Tris- $\mathrm{HCl}(\mathrm{pH}$ 7.4) containing $2 \mathrm{mM}$ EDTA $(2 \times \mathrm{TE}$ buffer). A small area on the chip was heated with IR laser $(10,25,50$ and 100 $\mathrm{mW}$ on the surface of the chip) using the microscopy system. After IR irradiation, a $4-\mu \mathrm{L}$ drop of solution from the heated spot was collected into a vessel.

The recovered DNA in the drop was amplified to check quantity. PCR amplification was carried out under the same conditions as described above. The products of this amplification were checked by electrophoresis using a $2 \%$ agarose gel followed by staining with $0.5 \mu \mathrm{g} / \mathrm{mL}$ ethidium bromide and analyzed with a fluorescence-image ana- lyzer (FM-Bio ${ }^{\circledR}$ 100; Hitachi Software Engineering, Tokyo, Japan).

\section{Rehybridization of Fluorophore- Labeled DNA with an SSDNA on the Microchip}

A 60-nucleotide fluorophore-labeled oligomer ssDNA (60-nucleotide sample DNA) complementary to the $60 \mathrm{nu}$ cleotides from the 3 '-end of the immobilized strand on the DNA chip was diluted to $2 \mu \mathrm{M}$. For rehybridization, the solution was dropped on the chip surface and incubated for $3 \mathrm{~min}$ at $60^{\circ} \mathrm{C}$. After rehybridization, the chip was rinsed with $2 \times$ TE buffer at room temperature and analyzed using the microscopy system.

\section{RESULTS AND DISCUSSION}

The purpose of this study was to demonstrate the feasibility of denaturing and extracting sample DNA from a small area by a photo-thermal denaturation procedure. First, we examined the efficiency of denaturation of sample DNA from the chip surface with a conventional heating procedure using a heat block. When the chip was maintained at $95^{\circ} \mathrm{C}$ for $1 \mathrm{~min}$, all of the sample DNA, which had been hybridized to the surface-bound probe DNA, was released from the chip surface (Figure 3, $a$ and $b$ ). As shown in Figure 3b, more

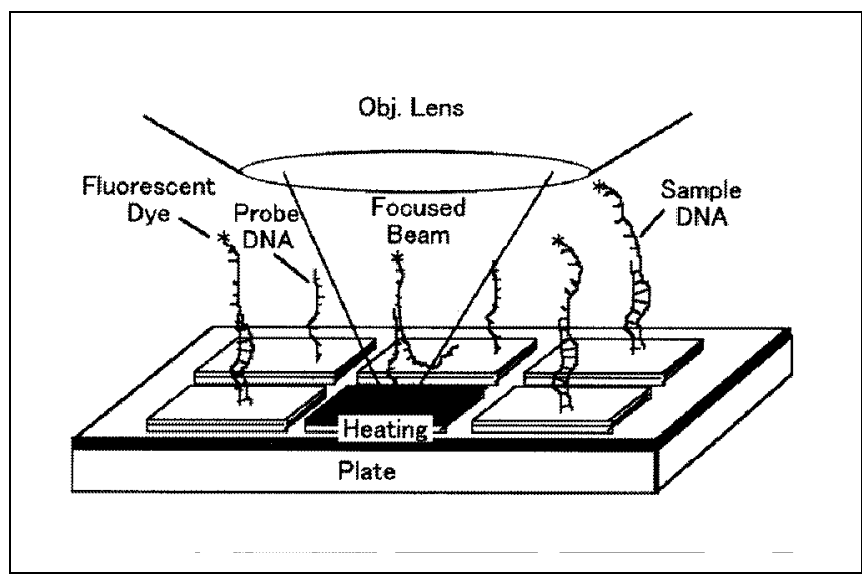

Figure 1. Schematic drawing of the photo-thermal denaturation method. First, the target DNA sample is captured by the immobilized probe DNA on the microchip surface. After the area for spot heating is selected by fluorescence microscopy, the area is heated by irradiation with an IR laser. The sample DNA released into the solution is collected and used for further analysis. The chosen DNA samples attached to the particular area on the chip surface are released by spot heating, which is controlled by the IR focused beam.

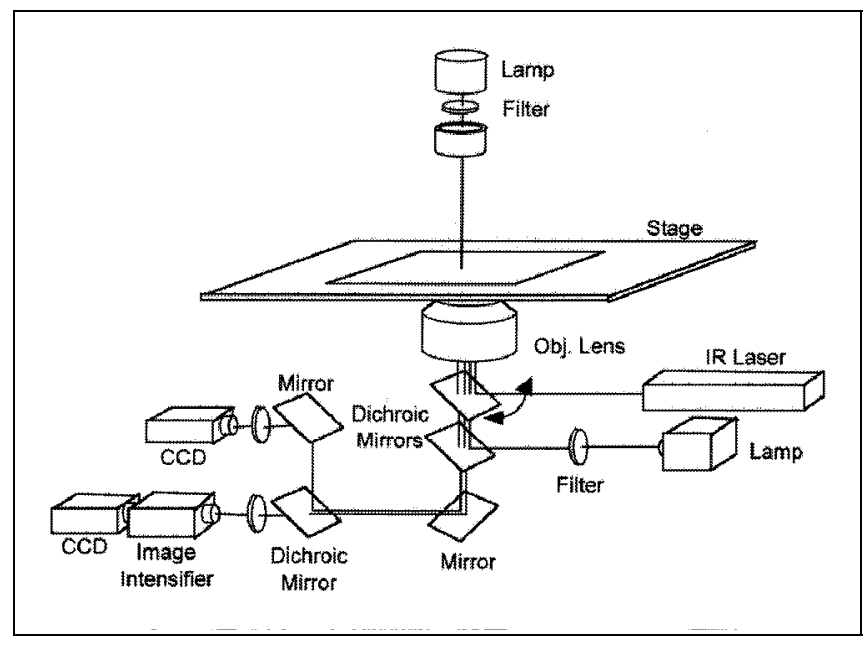

Figure 2. Schematic drawing of the photo-thermal denaturation microscopy system for area-specific extraction of surface-bound DNA. The microscope has three different optical units for phase-contrast, fluorescence and IR laser irradiation (5,7). Dichroic mirrors and band-pass filters direct the beams of the three different wavelengths of light. 


\section{Research Report}

than $95 \%$ of the fluorescent sample DNA was released from the chip surface. Next, a 2- $\mu \mathrm{M}$ 60-nucleotide sample DNA in $50 \mathrm{mM}$ Tris- $\mathrm{HCl}(\mathrm{pH} 7.5)$ was loaded onto the chip and successfully rehybridized with the surfacebound probe DNA (Figure 3c). The results indicate the following two facts. First, the integrity of the probe DNA remained intact, with the whole strands undamaged even after denaturation, as indicated by the 60 -nucleotide sample DNA successfully attaching to the 3 'end (free end) of probe DNA. Second, the chromium-coated microchip served as a good substrate for the immobilized probe DNA and could release almost $100 \%$ of sample DNA, and $70 \%$ could be rehybridized on average through the thermal denaturation and renaturation steps. Note that the proportion of irreversibly attached sample DNA on the chromium-coated chip is negligibly small in contrast to the glass surface (Figure 3d). As shown in Figure 3d, the amount of undetached sample DNA on the glass surface was $90 \%$ after the denaturation process, in strong contrast to the case with the chromium-coated surface, which was less than 5\%. This may

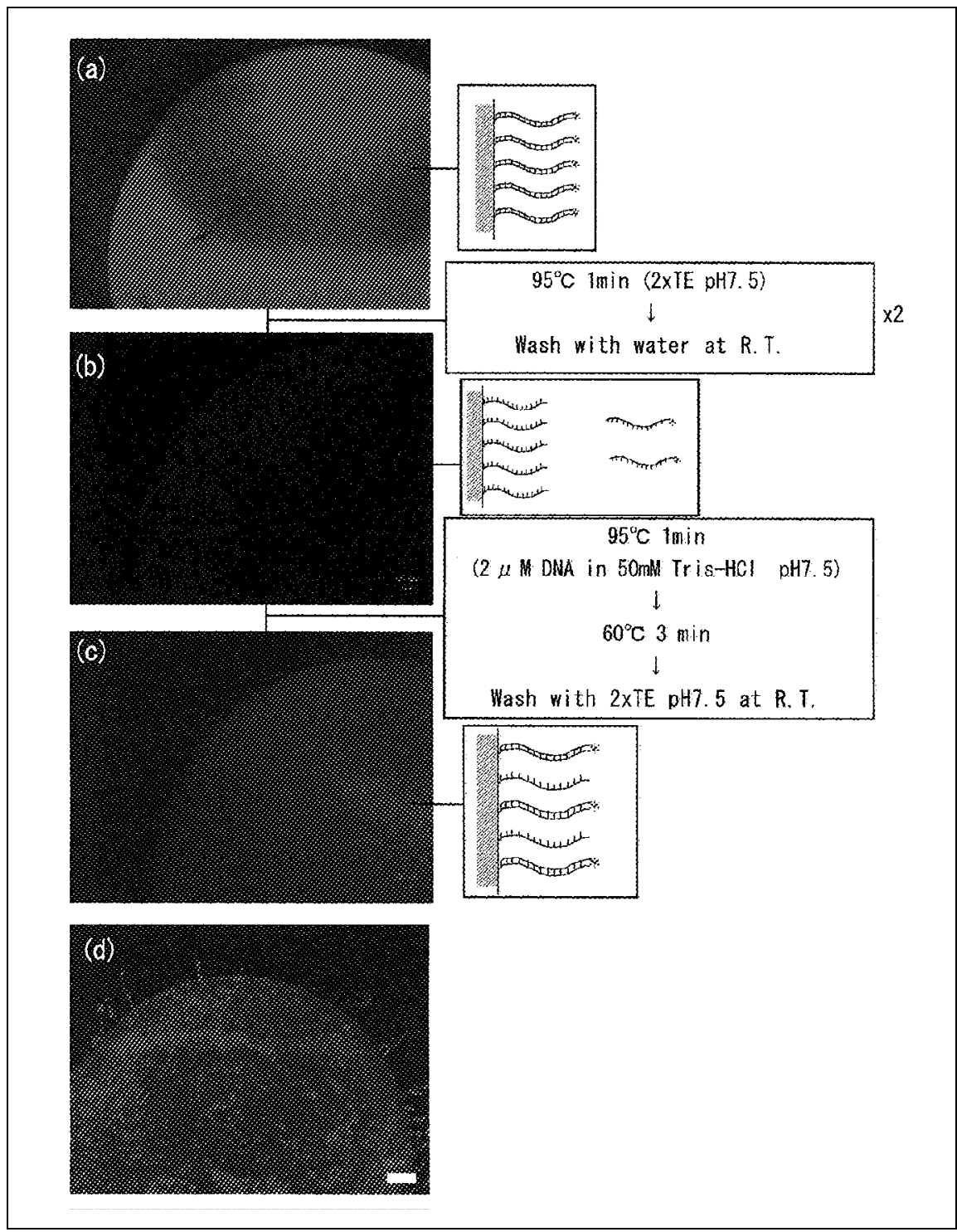

Figure 3. Fluorescence micrographs of the chromium-coated microchip surface and glass surface. (a) Fluorescence image of the chromium-coated microchip with attached fluorescent DNA; (b) the chip after the photo-thermal denaturation process; (c) the chip after rehybridization with the sample; and (d) the glass surface after the denaturation process. Bar, $200 \mu \mathrm{m}$.
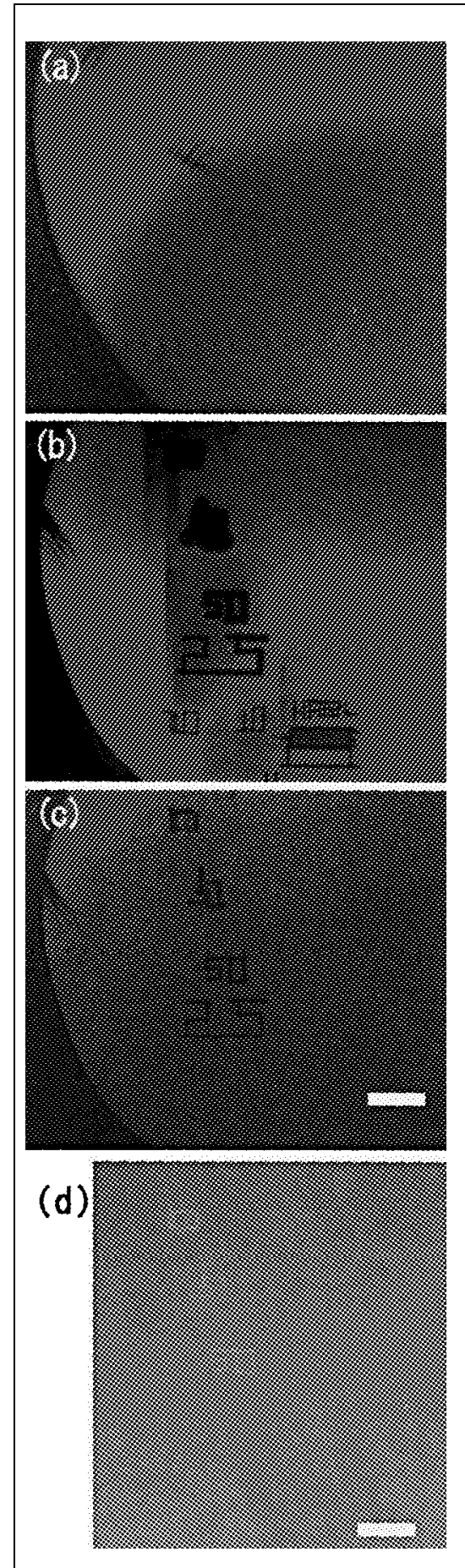

Figure 4. Fluorescence and phase-contrast micrographs of the microchip surface. Fluorescence image of the microchip surface before (a) and after (b) IR laser beam irradiation; (c) the chip after rehybridization with the sample DNA on the IR-irradiated microchip; and (d) phasecontrast micrograph of (c). The numbers traced on the surface of the chromium-coated microchip $(100,50,25$ and 10 , respectively) indicate the power of IR laser irradiation for tracing, 100, 50, 25 and $10 \mathrm{~mW}$. The word "HARL" was traced with a 10-mW IR laser beam. Bars, $100 \mu \mathrm{m}$. 
be due to the charge of chromium (zeta potential) at the boundary of the chip surface, which prevents the nonspecific adsorption of sample DNA directly onto the chip surface.

The chromium-coated microchip has three advantages in the photo-thermal denaturation method. The first is its improvement of the absorbance of the IR laser on the surface of the chip during heating. While absorbance of a glass slide and water is negligibly small at $1053 \mathrm{~nm}$, the 6-nm-thick chromiumcoated surface achieved $40 \%$ absorption of the IR laser. The second advantage is the high efficiency of silane coupling on the oxydized chromium at the surface of the plate compared with that of the glass surface. In general, silane coupling works far more efficiently on a metal oxide than a glass surface. The third advantage is, as mentioned above, the prevention of nonspecific DNA adsorption.

Before photo-thermal spot heating, the fluorophore-labeled 619-nucleotide ssDNA (standard sample DNA), the complementary pair of whole-length probe DNA was hybridized onto the chromium-coated chip (Figure 4a). Importantly, although the whole area of the microchip was exposed to the standard sample DNA solution, the DNA attached only to the area coated with probe DNA. Next, the 1053-nm

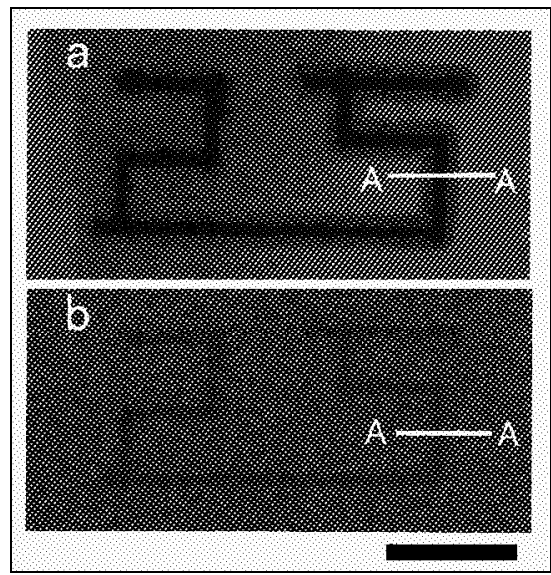

Figure 5. Fluorescence micrographs and intensity profiles of the $25-\mathrm{mW}$ IR-irradiated microchip surface. (a) Fluorescence image of the microchip surface after $25 \mathrm{~mW}$ IR laser irradiation (magnified from Figure 4b); and (b) the chip after rehybridization with the sample DNA on the IR-irradiated microchip (magnified from Figure 4c). Bar, $100 \mu \mathrm{m}$. focused IR beam irradiated the surface of the chip and scanned it with varying laser power (10-100 $\mathrm{mW}$ ) (Figure $4 \mathrm{~b}$ ). Bubbles generated by boiling water were sometimes observed at the irradiated area, indicating that the temperature of solution in the focused area exceeds boiling point. Figure 5a shows a magnified image of the area irradiated at $25 \mathrm{~mW}$ in Figure 4b. Figure $6 \mathrm{a}$ is the trace of fluorescence intensity along the line A-A in Figure 5a. As shown in Figures $5 \mathrm{a}$ and $6 \mathrm{a}$, fluorescence intensity decreased in two steps, first to less than $30 \%$ in region $\mathrm{P}$ with a width of 30 $\mu \mathrm{m}$ and then to less than $5 \%$ in region
Q with a width of $10 \mu \mathrm{m}$.

After photo-thermal extraction, we examined whether the probe DNA is maintained intact after IR irradiation by rehybridizing the 60-nucleotide sample DNA. Figure $4 \mathrm{c}$ shows the result of rehybridization between the 60-nucleotide sample DNA and the probe DNA after 10-100 mW IR laser irradiation. As analyzed in the $25-\mathrm{mW}$ case (Figure $5 \mathrm{~b}$ and Figure $6 \mathrm{~b}$ ), fluorescence intensity in region $\mathrm{P}$ recovered to the original level after the rehybridization procedure (width R), but the intensity in region $\mathrm{Q}$ did not. Thus, although all nonfluorescent lines traced by the IR beam

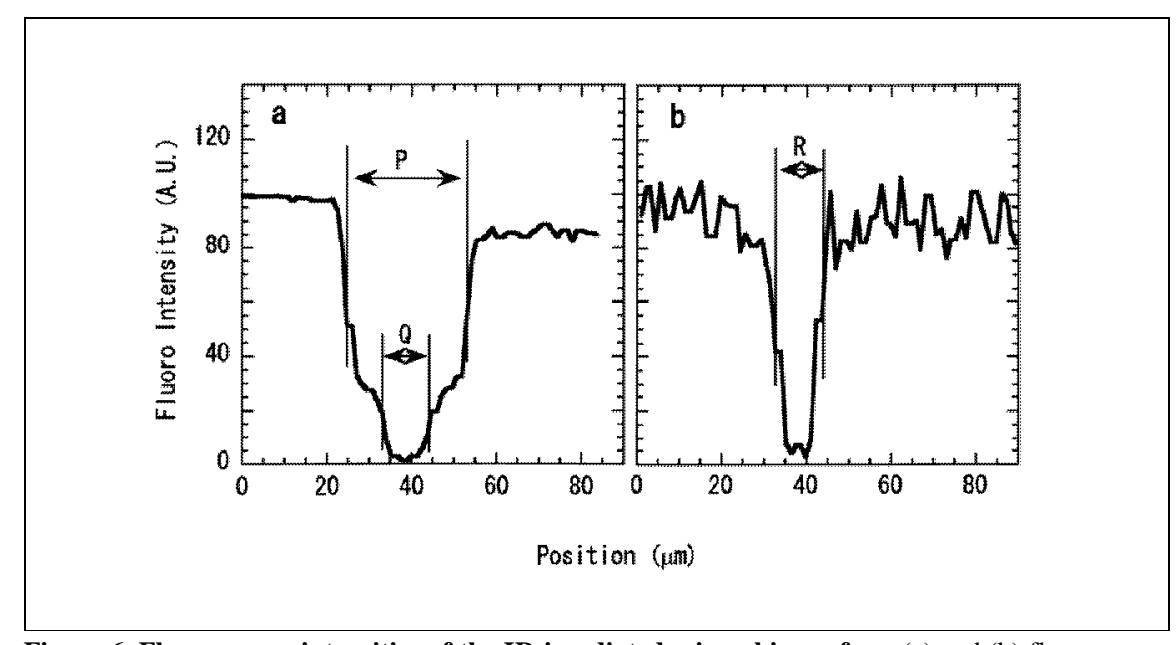

Figure 6. Fluorescence intensities of the IR-irradiated microchip surface. (a) and (b) fluorescence intensity profile along the A-A line in Figure 5, a and b, respectively.

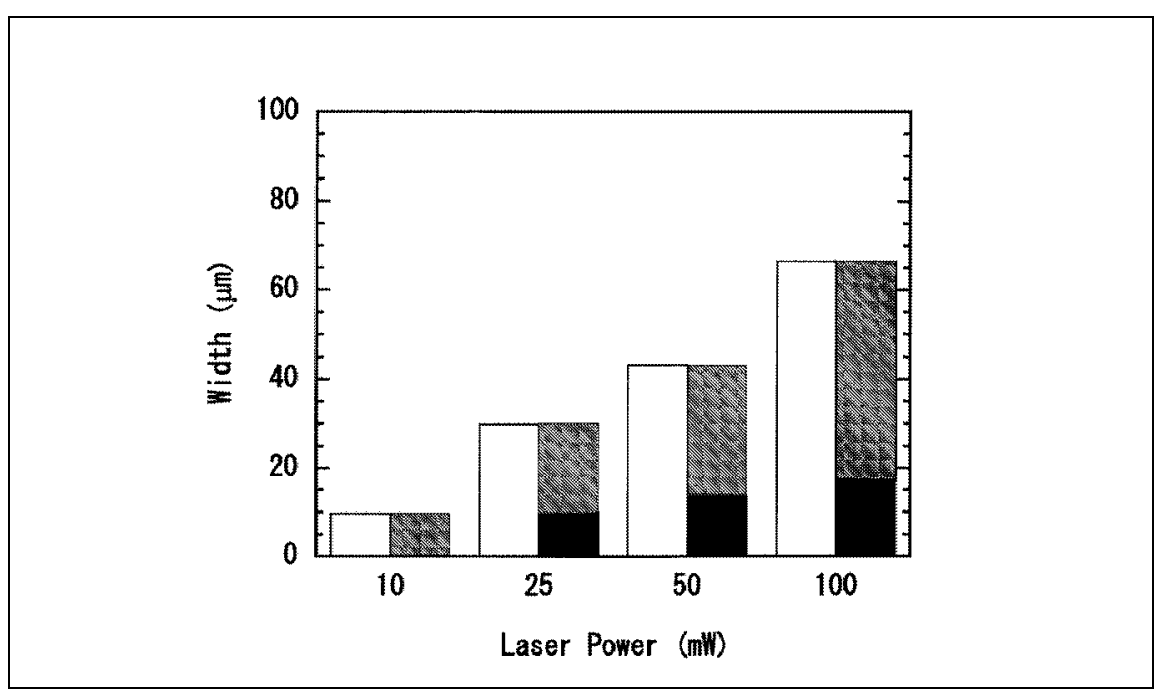

Figure 7. Laser power dependence of DNA denaturation on the microchip surface. Open box, width of the denatured area of the fluorophore-labeled sample DNA after IR irradiation; closed box, width of the damaged area on which no rehybridization occurred after rehybridization; hatched box, width of the rehybridized area after rehybridization. 
at greater than $10 \mathrm{~mW}$ remained even after the rehybridization process, those traced at $10 \mathrm{~mW}$ were completely redecorated with fluorophores (Figure $4 c)$. The width of the traced lines increased as laser power increased (Figure 7). A phase-contrast image (Figure 4d) shows that the chromium film was damaged by IR irradiation stronger than $10 \mathrm{~mW}$. These results demonstrate that the probe DNA remains undamaged after IR irradiation unless the chromium coating has been damaged.

Finally, we measured the amount of sample DNA extracted from the chip after spot-heating a $100 \times 10 \mu \mathrm{m}$ area with a $10-\mathrm{mW}$ IR focused beam. From fluorescence intensity analysis of the beam, more than $70 \%$ of the sample DNA was released from the chip surface after irradiation. As shown in Figure 8 , the total amount of extract was in the order of $10^{-17} \mathrm{~mol}$, on the basis that the fluorescence intensity of the extracted sample DNA was between that of the $1 \times 10^{-16} \mathrm{~mol}$ and $1 \times 10^{-17} \mathrm{~mol}$ reference samples after 15 cycles of PCR amplification. This result indicates that this photo-thermal denaturation extracted at least one DNA molecule from a 13 $\times 13 \mathrm{~nm}^{2}$ area $\left(10^{-17} \mathrm{~mol} / 1000 \mu \mathrm{m}^{2}\right)$ and further indicates that this method allows the area-specific extraction of a

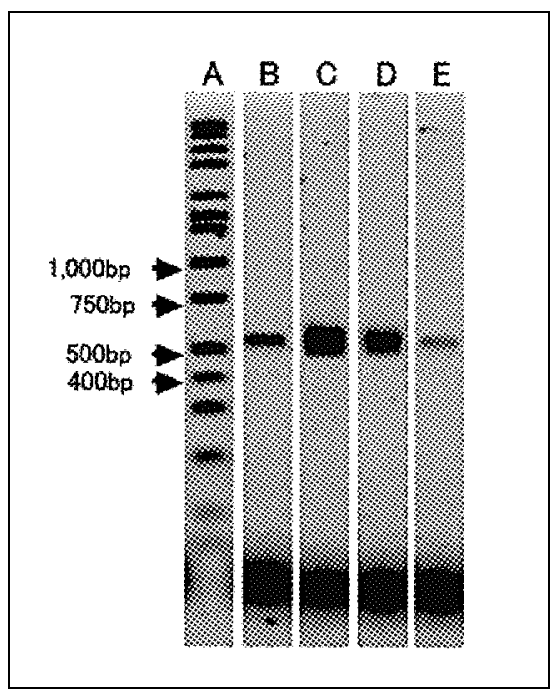

Figure 8. Agarose gel electrophoresis of PCR products amplified from the microchip extract. Five microliters of the DNA products were applied to a $2 \%$ agarose gel. Lane A, DNA molecular markers; lane B, sample DNA extracted from $10^{3} \mu \mathrm{m}^{2}$ microchip surface; lanes C-E, concentration references, $1 \times 10^{-15}, 10^{-16}$ and $10^{-17}$ mol of the same DNA, respectively. specified sample DNA.

The present study shows the potential of this DNA chip as a DNA purification apparatus. Spatial resolution of the denaturation spot size can be improved by increasing the objective lens magnification. We feel that this photothermal method will greatly enhance separation efficiency of different DNA from crude samples.

\section{ACKNOWLEDGMENTS}

We thank Drs. K. Miyauchi, T. Iwayanagi and T. Sakamoto of Hitachi, Ltd. for their support, and Dr. G. Harris for English editing. We also thank Prof. K. Kinosita, Jr. of Keio University and Dr. T. Nishizaka of Core Research for Evolutional Science and Technology (CREST) for their cooperation in consulting on the microscopy system. This research was partly supported by Grants-in-Aid for Scientific Research, for Scientific Research on Priority Areas and for the High-tech Research Center Project from the Ministry of Education, Science, Sports and Culture of Japan [grant no. 11559016 to S.I., no. 11878129 to S.I. and no. 11CE2006 (Komaba Complex Systems Life Science Project) to K.K.] and Grants-inAid from the Japan Science and Technology Corporation (CREST).

\section{REFERENCES}

1.Burns, M.A., B.N. Johnson, S.N. Brahmasandra, K. Handique, J.R. Webster, M. Krishnan, T.S. Sammarco, P.M. Man et al. 1998. An integrated nanoliter DNA analysis device. Science 282:484-487.

2.Cheng, J., E.L. Sheldon, L. Wu, A. Uribe, L.O. Gerrue, J. Carrino, M.J. Heller, and J.P. O'Connel. 1998. Preparation and hybridization analysis of DNA/RNA from $E$. coli on microfabricated bioelectronic chips. Nat. Biotechnol. 16:541-546.

3.Kambara, H. 1998. Recent progress in fluorescent DNA analyzers and methods. Curr. Topics Anal. Chem. 1:21-36.

4.Kato, H., T. Nishizaka, T. Iga, K. Kinosita Jr. and S. Ishiwata. 1999. Imaging of thermal activation of actomyosin motors. Proc. Natl. Acad. Sci. USA 96:9602-9606.

5.Kinosita, K., Jr., H. Itoh, S. Ishiwata, K. Hirano, T. Nishizaka and T. Hayakawa. 1991. Double-view microscopy with a single camera: real-time imaging of molecular orientations and calcium. J. Cell Biol. 115:67-73.

6.Lockhart, D.J., H. Dong, M.C. Byrne, M.T. Follettie, M.V. Gallo, M.S. Chee, M. Mitt- mann, C. Wang et al. 1996. Expression monitoring by hybridization to high-density oligonucleotide arrays. Nat. Biotechnol. 14:16751680.

7.Nishizaka, T., H. Miyata, H. Yoshikawa, S. Ishiwata and K. Kinosita, Jr. 1995. Unbinding force of a single motor molecule of muscle measured using optical tweezers. Nature 377:251-254.

8.O'Donnell, M.J., K. Tang, H. Koster, C.L. Smith and C.R. Cantor. 1997. High-density, covalent attachment of DNA to silicon wafers for analysis by MALDI-TOF mass spectrometry. Anal. Chem. 69:2438-2443.

9.Service, R.F. 1998. Microchip arrays put DNA on the spot. Science 282:396-398.

10.Wang, D.G., J.-B. Fan, C.-J. Siao, A. Berno, P. Young, R. Sapolsky, G. Ghandour, N. Perkins et al. 1998. Large-scale identification, mapping, and genotyping of single-nucleotide polymorphisms in the human genome. Science 280:1077-1082.

Received 5 March 1999; accepted 1 December 1999.

\section{Address correspondence to:}

Dr. Kenji Yasuda

Department of Life Sciences

Graduate School of Arts and Sciences

The University of Tokyo

3-8-1 Komaba, Meguro

Tokyo 153-8902, Japan

Internet: cyasuda@mail.ecc.u-tokyo.ac.jp 